\title{
The Effects of Using Manipulatives on Students' Learning in Problem Posing: The Instructors' Perspectives
}

\author{
Hyunkyung Kwon \\ Mary Margaret Capraro \\ Texas A\&M University \& Aggie STEM, USA
}

Problem-posing skills are becoming increasingly important for students to attain for success in mathematics as acquiring such skills aids in improving students' critical thinking ability and mathematical proficiency. A study was conducted at an elementary school in central Texas. Trained researchers administered research-based intervention activities to determine the effects of such strategies on $2^{\text {nd }}-5^{\text {th }}$ grade students' problem-posing and -solving skills. In the current study, two researchers who had been involved in the larger aforementioned quasi-experimental study interviewed researchers who had also assisted in conducting that study. They selected trained researchers from the previous study who used only manipulatives with the groups that they administered problem-posing intervention to students. These selected participant researchers, were interviewed to determine their perspectives of the students' experiences while using manipulatives during problem posing activities. The findings indicate that using manipulatives can be an effective instructional strategy when conducting problem-posing activities. Results show students' motivation improved, and their engagement and excitement increased during the learning process.

Keywords: problem posing, elementary education, manipulatives, concrete manipulatives

Problem-solving and problem-posing skills are important for students to acquire for success in mathematics. Problem solving has been part of educational standards at all grade levels (El Sayed, 2002; National Council of Teachers of Mathematics [NCTM], 1989), and researchers have increasingly found problem posing to be crucial in developing students' critical thinking ability, computational skills, and mathematical knowledge (English, 1997; Rosli, Capraro, \& Capraro, 2014; Singer \& Voica, 2012; Van Harpen \& Presmeg, 2013). Thus, it is important that mathematics educators use effective instructional strategies when conducting problem-solving and problem-posing activities. 
Problem-posing activities are effective and beneficial in developing students' mathematical abilities; they allow students to integrate, analyze, and display mathematical concepts (Van Harpen \& Presmeg, 2013). Research showed that incorporating problem-posing activities into mathematics lessons positively affected students' mathematics learning (Rosli et al., 2014; Stoyanova, 2003; Van Harpen \& Presmeg, 2013). However, teachers' guidance and readiness in problem-posing instruction also affected students' level of achievement (Lowrie, 2002). Therefore, it is important to educate pre-service teachers on problem-posing strategies and instruction.

The NCTM (2000) has recommended using manipulatives as teaching tools to teach mathematical concepts at every grade level. Concrete manipulatives, such as dried beans, pattern blocks, Unifix cubes, fraction strips, and counters can be used in elementary mathematics classrooms. Research has shown that students at all grade levels can benefit from using manipulatives when learning mathematics (Carbonneau, Marley, \& Selig, 2013; NCTM, 2000). However, manipulative cannot be used in isolation. When students did not connect activities involving manipulatives with learning goals, no positive effects were shown in their achievement (Carbonneau et al., 2013; Rosen \& Hoffman, 2009). Therefore, teachers should plan and structure activities appropriately to explicitly align the use of manipulatives with the learning objectives.

Using manipulatives when teaching is a constructivist educational approach. Educational philosophers believe that learning is a process in which a student's knowledge is constructed and actively developed by the student rather than passively received by the student (Bruner, 1964; Dewey, 1938; Piaget, 1964). From this perspective, students are active investigators rather than passive recipients in the learning process (Dewey, 1938). When educators used manipulatives in their classrooms, students were encouraged to be active in the learning process because they were able to touch the concrete manipulatives (Carbonneau et al., 2013; Krapp, 2005). Thus, using manipulatives to facilitate students' mathematical understanding can strengthen students' problem-posing and problem-solving abilities.

Young students do not have the ability to think abstractly (Bruner, 1964; Carbonneau et al., 2013). However, use of manipulatives may provide a muchneeded solution for young learners who are faced with abstract concepts. Researchers have found that students who used manipulatives actively developed their understanding and bridged the gap between the abstract and concrete because they were able to visualize the mathematical concept through building models with the manipulatives (Ausubel, 1963; Bruner, 1964; Carbonneau et al., 2013; Krapp, 2005; Schoenfeld, 1987). Thus, when students have the opportunity to use concrete manipulatives as learning tools, they can enhance their abstract thinking ability.

In addition to enhancing students' abstract thinking ability, students' use of manipulatives can also increase their level of interest and motivation, which 
is a critical factor influencing students' success in mathematics. Many students in the United States lack interest in mathematics (Carbonneau et al., 2013; Krapp, 2005). Krapp (2005) has shown how manipulatives have been a way of engaging and involving students in a fun learning experience. In addition, NCTM (2002) has encouraged mathematics educators to use manipulatives to motivate students. Therefore, it is important for mathematics educators to use quality manipulatives to not only positively impact students' interest in learning, but to also encourage them to become effective problem solvers.

Because motivating students in the learning process is important, educators should recognize when students' motivation and interest increase. Krapp (2005) stated that students' interest and intrinsic motivation developed when they experienced engagement in the activity in a positive way. The process of students learning mathematics through hands-on activities was considered a situational factor that awakened students' mathematical interest (Krapp, 2005; Rosen \& Hoffman, 2009). Moreover, students developed interest when they perceived the activity as meaningful (Krapp, 2005). Therefore, students' interest and motivation can grow if students perceive learning as enjoyable, important, and stimulating.

Despite the advocacy of using manipulatives and the importance of problem-solving and -posing abilities, there have been few rigorous published research studies on the use of manipulatives with problem-solving and -posing activities. Therefore, the purpose of the current study was to investigate the use of manipulatives within the problem-posing learning experiences of elementary students from the perspective of the researchers who had administered the problem-posing intervention to the students with the use of manipulatives during the previous quasi-experimental study. Henceforth, these researchers will be referred to as the "instructors".

\section{Definition of Terms}

For the purpose of this study, the following terms have been defined:

- Concrete Manipulatives- Physical objects that are used as teaching tools to engage students in the hands-on learning of mathematics

- Problem Posing- The process of constructing mathematical interpretations of concrete situations and formulating them as meaningful mathematical problems (Stoyanova, 2003)

\section{Research Questions:}

1. What are the instructors' perspectives on the experiences of elementary students when learning problem posing with manipulatives?

2. What benefits do the elementary students gain when they use manipulatives during the process of learning mathematical concepts like problem posing? 


\section{Methodology}

The current study was based on a quasi-experimental study that a research team in central Texas conducted. In the previous quasi-experimental study, $2^{\text {nd }}-5^{\text {th }}$ grade students were randomly assigned to either the problemposing or -solving intervention group. Trained research team members were also randomly assigned to one of the respective grade levels to conduct an intervention for 10 weeks. In the current study, two researchers who had been involved in the aforementioned quasi-experimental study interviewed three instructors who had also assisted in conducting that study and used manipulatives in their intervention with the problem-posing group of students. The three instructors were interviewed to determine their perspectives of the student experience in using manipulatives while problem posing.

\section{Participants}

The previous study was conducted with 119 elementary school students (grades 2-5) at a rural public elementary school in central Texas during the spring of 2017. The demographics of this school district consisted of African American (31\%), Hispanic (25\%), and White (42\%) students; the remainder of the students provided no specific ethnicity (2\%). Of these students, $66 \%$ were economically disadvantaged. Prior to conducting this study, informed consent was gathered from all of the students and their parents.

The researchers, or instructors, from the previous study were recruited using snowball sampling. A volunteer instructor was recruited, and on his or her turn, that instructor suggested other instructors from the previous study who met the necessary criteria who might have different opinions or experiences from administering the problem-posing intervention using manipulatives. Based on this sampling method, nine instructors were found. Of those nine, only three instructors agreed to participate in the present study. The three instructors were female Ph.D. students in central Texas. Each had previous experience as classroom teachers at the K-12 level, and each had earned a master's degree in mathematics education. Prior to assisting with the previous quasi-experimental study, these instructors received training on mathematical content and teaching methods. They then used this training when implementing instruction with manipulatives into the problem-posing intervention.

\section{Instruments}

The instrumentation included interviews with instructors for data collection in this research study. Interview questions were developed by the researchers using open-ended questions based on the description of best practices in developing interview protocol. Researchers conducted the interviews via email or Skype and administered the interviews using a semistructured interview protocol (Appendix A), which was developed by the first researcher. Each interview lasted from 30 minutes to an hour. An audio 
recording device and computer template for field notes were used when conducting the Skype interviews. The recording device was started at the beginning of the Skype interviews after the instructors had been welcomed. After each instructor answered the questions, the first researcher asked if they had any further information they wished to provide. Once all of the questions were answered, the recording device was stopped and the instructors were thanked for their participation.

In addition to the interview, the instructors' observation notes taken during the intervention were also used to analyze students' learning experiences. The instructors recorded any behavior, academic success or struggle, environment, and anything that occurred during the lesson in their observation notes. The notes collected from the instructors were analyzed to determine the effectiveness of manipulatives used during problem-posing activities. Finally, the researchers obtained a signed consent form from each instructor that included their names and contact information, in case of the need for follow-up data.

\section{Intervention}

The intervention of the previous study took place every Tuesday and Thursday for 10 weeks. During this time, students in the problem-posing intervention group participated in a variety of problem-posing activities over the course of 13 lessons. The duration of the lessons was 15 to 20 minutes, depending on how many groups were at a particular grade level. Each group consisted of 4 to 5 students. Students had an opportunity to become engaged in using concrete manipulatives, pictures, equations, graphs, and real-life materials. For the current study, researchers focused exclusively on problemposing lessons in which instructors provided students with concrete manipulatives to use in problem-posing activities such as pattern blocks, Cuisenaire Rods, base ten blocks, Unifix cubes, fraction strips, counters, and real-life materials.

During the problem-posing activities, students were asked to pose 1 to 2 problems using the provided manipulatives. In this study, the researchers focused on the activities in which students used both concrete manipulatives, as models, and real-life materials to pose grocery-shopping problems. Students were allotted 10 minutes to pose problems; afterwards, they were able to share their problem-generating process with their peers. In addition, they discussed the process of integrating mathematical concepts into their posed problems.

\section{Data Collection}

In order to determine the instructors' perspectives when using manipulatives to teach problem-posing skills, a qualitative methodology was used to analyze the gathered data. In the previous study, student participants were recruited from an independent school district (ISD) in the central part of Texas. During the recruitment process, the researchers provided them with 
information about the study and consent forms. Students who did not sign the consent forms or who did not agree to participate in the study were eliminated from the study and participated in their regular mathematics class. The instructors took observation notes during every lesson. In the present study, these notes were gathered from the three instructors and included to analyze students' behavior and skills. Interviews of the instructors who used manipulatives as an intervention during the lessons were also included. There were nine instructors who administered problem-posing intervention in the previous study. Of those instructors, three used manipulatives in their intervention strategy. Each of those three instructors voluntarily participated in an interview. The three instructors administered problem-posing in grades 2 through 5 and had approximately 20 students in their classrooms. Their contact information was gathered to schedule a time for their interviews. Each interested instructor was scheduled to participate in an email interview or a Skype interview with the researcher in order to gather in-depth information. The interview protocol was carefully read before conducting the scheduled meetings with the participants. A consent form was obtained from each of the participants during the interviews. During the auto-recorded interviews, the interviewer used a semi-structured interview protocol.

\section{Data Analysis}

The data obtained from the three interviews and the instructors' observation notes were analyzed. The interviews were transcribed and analyzed using Miles and Huberman's (1994) data analysis model. The data analysis included the following phases: data reduction, data display, and conclusion drawing and verification. During the data reduction phase, which occurred continuously throughout the analysis, the researcher edited, segmented, and summarized the data. Once the data were coded, patterns that appeared to be important were categorized into themes. After the two previous phases were completed, the researcher was able to draw possible conclusions. Possible conclusions that were drawn in the early stage of analysis were verified and finalized once all the data have been analyzed.

\section{Findings}

For the purpose of protecting the identity of the instructors, pseudonyms are used for all three teachers: Instructor A, Instructor B, and Instructor C. Interview notes and instructor's observation notes were analyzed to answer the first research question, which is trying to find out instructors' perspective on elementary students' experience learning problem posing with manipulatives. To answer the second question concerning whether elementary students have benefits using manipulatives during the process of learning mathematical concepts, same data were analyzed. Researchers have organized the findings into themes from the interviews and observation notes. 


\section{Manipulatives}

Elementary students tend to require strong classroom management and guidance. In the present study, direct, verbal instruction alone was not effective in maintaining students' focus during a lesson; most of the students required a visual demonstration or example to help them understand the instructions. Instructor A said, "Manipulatives are a useful tool to make mathematics real and relatable." She also mentioned that mathematics is sometimes abstract, and it is hard for younger students to understand certain topics. Instructor B agreed with Instructor A by stating, "Students did not have the abstract thinking ability." Therefore, when they modeled their problem using concrete manipulatives, it helped them to bridge their abstract and concrete thinking. Instructor A also mentioned in her observation notes that students were able to visualize the key concepts or key components of a concept through use of manipulatives. In addition, she said that, in general, subtraction can be hard for $2^{\text {nd }}$ graders, but her students seemed to see and comprehend how subtraction works through the use of manipulatives. Moreover, Instructor C said that, "manipulatives helped students conceptualize difficult concepts." Using the building blocks to conceptualize the complicated mathematical expressions allowed them to see the process of the multi-step problem. In her notes, she wrote that a student used building blocks to represent cookies, and the student was able to see the process of getting more cookies when using the cookies to model her addition problem. Thus, the instructors believed incorporating manipulatives into a lesson could help students visualize the mathematical concepts.

Although manipulatives allowed students to better visualize and understand mathematical concepts by modeling them, instructors must be well prepared and confident in teaching manipulative-based problem posing to utilize this method effectively with students. All three instructors mentioned how students were using the concrete manipulatives to model the problem and test the problem's appropriateness before they actually posed the problems. This shows that if instructors are prepared enough to effectively implement manipulative-based instruction, students will be able to pose better problems with manipulatives. Instructor B said that when she guided the discussions clearly, students tended to become good storytellers, or explain their mathematical process better, by showing their models when they shared their problems with their peers. Instructor $C$ had similar thoughts on how teachers should prepare the activity to become "student-led and provide students time to explore the content with the manipulatives and make discoveries on their own." However, Instructor A noted, "Teachers have to feel comfortable enough with their knowledge of manipulatives and the content in order to use them effectively." Therefore, when teachers are confident enough to use manipulatives in classroom activities, students may benefit from the activities by actively learning and choosing to model the mathematical concepts. 


\section{Student Motivation}

Manipulatives seemed to foster student motivation. In all of Instructor A, B, and C's observation notes, they mentioned their students' high engagement in activities. The instructors noted that students tended to be more motivated in lessons when they were able to touch and use the manipulatives. Instructor A observed how the students seemed to be more excited when they were completing the grocery shopping activity with manipulatives compared to other problem-posing activities in which they used mathematical equations or graphs to represent the posed problems. Moreover, Instructor B noted that they were excited about the fact that they were able to select which of the available concrete manipulatives they wanted to use to model their problems. For example, she said, "some students wanted to choose the colorful building blocks" to represent different food type such as cookies, ice cream, and candies. Instructor C said, "Students were excited to be creative when problem posing. They seemed to be more successful in learning mathematical concepts because they were more excited to learn and practice their mathematical skills." From the observation notes, each of the instructors noted that students seemed to be more excited and engaged during lessons, which influenced their motivation. Thus, it allowed them to become more successful in problem posing.

All three instructors discussed the effectiveness of using manipulatives for problem-posing activities. Instructor A also noticed that when students used manipulatives, they were usually "more attentive and wanted to figure out the answer" or use the manipulatives to understand the concepts. Instructor B likewise observed that students were "more excited and motivated" when using manipulatives. She realized that students were engaged in the lesson because they were able to connect the manipulatives to real-life scenarios and had opportunities to apply their personal experience to the problems. Moreover, students' increased motivation was so notable that instructors mentioned it in their observation notes during the intervention as well as after the intervention during their interviews.

Although the instructors realized the effectiveness of using manipulatives, they also noticed some of the students were not able to connect manipulatives with mathematical concepts. For example, Instructor A stated, "Some students do get distracted, but this mainly goes back to teaching routines and procedures about using manipulatives and staying on task." Instructor B also had concerns about students focusing more on the actual manipulative rather than how to use it in their posed problems. In her observation notes, she also wrote that several students did not incorporate their manipulative into the problems they generated. Two instructors had concerns regarding student behavior, and all three instructors thought secondary students would benefit more from the use of manipulatives because mathematics becomes more abstract in secondary levels and having a manipulative to visualize can be helpful. Overall, all the instructors noted in their observation notes that certain 
students were easily distracted with the manipulatives, and those who were distracted had a hard time relating the manipulatives to mathematical concepts.

\section{Problem-Posing Strategies}

As students became more comfortable sharing their problems with peers, their problem posing skills seemed to increase. Instructor A stated, "Students were getting more confident in their problem-posing skills." Using manipulatives facilitated a richer discussion, which helped students to become better problem posers due to the opportunity to evaluate and process their mathematical thinking verbally with peers while using visual modeling. Instructor B said that students tended to "learn from each other" when they shared their problems with their peers effectively. By sharing the steps of how they posed the problem using manipulatives, students were able to critique each other's problems. Instructor $\mathrm{C}$ wrote about how students were pointing out the missing information in their peers' posed problems. For example, Instructor $\mathrm{C}$ mentioned that, in one instance, students pointed out that a peer presenting his problem did not represent the portion of fraction correctly by only moving three colored chips when he was supposed to move four of them. Thus, using manipulatives during the activities allowed students to have effective discussions that ultimately increased students' problem-posing skills.

As students were learning different strategies from each other, Instructor B noticed how students benefitted when their learning included different reallife scenarios. Using manipulatives to model a scenario helped them to become better problem posers. Moreover, Instructor $\mathrm{C}$ talked about how the grocery shopping activity allowed students to apply their real-life experience, which ultimately allowed them to pose problems accurately. When students were involved with the grocery shopping activity, they were able to choose certain items such as grapes, cereal boxes, strawberries, toilet paper rolls, milk, water, etc. that cost a specified amount. When students had a budget to adhere to during their grocery shopping activity, they had to perform addition, subtraction, multiplication, and divisions with a real-life scenario. Because many students had previous knowledge and experiences of visiting grocery stores, this real-life scenario helped them to apply their previous knowledge in a mathematical context, which shows how using manipulatives has positive effect in problem posing. However, with those students whose experiences were limited due to age or various other factors in mind, Instructor $\mathrm{C}$ mentioned the benefit of problems based on real-life scenarios with real-world concrete objects may come from learning new information about the world. She said, "Being in a small town, it is easy to only know what is in your backyard. I think having the manipulatives and showing things like prices of food at the grocery store can help them learn more about the world." Even if students did not have direct experiences, they were able to learn from their peers during discussions. All instructors found that using manipulatives with real-life applications helped 
students to be more engaged in the learning process and allowed them to be creative and pose their own unique problems.

\section{Discussion}

Problem-posing is a helpful tool to assess students' mathematical skills. In this study, students were asked to write a word problem using manipulatives to explore students' problem-posing learning experience through using manipulatives. According to the observation notes from the instructors, most of the students were able to successfully pose word problems representing the models that they created. Previous research has shown that using manipulatives helped students to actively develop their understanding and bridge the gap between the abstract and concrete (Bruner, 1964; Carbonneau et al., 2013), and researchers found that it allowed students to visualize the process of mathematical expressions, which helped improve students' problem-posing skills. They integrated their mathematical knowledge when they modeled the problem before they posed the problem.

The findings of the current study in reference to student motivation and engagement align with results from prior research (Carbonneau et al., 2013; Krapp, 2005; Rosen \& Hoffman, 2009) which found that use of manipulatives could be a way of engaging students in a fun and exciting learning experience. Motivation was an important factor in the elementary school students' learning, and the activities in which students used manipulatives seemed to help students become more engaged in the learning process. Students were able to use their imagination and be creative when they posed problems because they were able to choose manipulatives that they were interested in.

Although students seemed to be more engaged in the lesson and were excited to learn, teacher guidance was important for the elementary students as was characterized in the interview. Although research has shown how students become more engaged in the learning activities when using manipulatives (Carbonneau et al., 2013; Krapp, 2005), researchers found that some students were excited to use the manipulatives, but did not use it educationally because they were distracted by the manipulatives. Students seem to be easily distracted if the use of manipulatives is not well aligned with lesson goals; thus, the activities of the lesson must match the learning goals to develop a successful problem-posing lesson. If students do not see a relation between the activity, which includes the manipulative, and the learning goal, using a manipulative does not provide any educational benefits. As there are some concerns with the use of manipulatives, the instructors realized the importance of teachers' guidance. Because the students were young learners, they needed guidance in the learning process. For example, a student could be overwhelmed with too many choices given to them. A teacher may share an example or may model a sample problem to provide students some clues and prompts. Furthermore, teacher preparedness for the lesson is also important. Connecting manipulatives 
with mathematical concepts is crucial as was demonstrated through the instructor interviews. When teachers are not prepared for connection, students are more confused and unable to apply mathematical knowledge when using manipulatives.

As long as teachers are well prepared and students use manipulatives as learning tools, manipulatives can develop students' interest, motivation, and engagement. However, to develop effective problem-posing skills, more time seems to be needed. If the intervention had been longer, and therefore included additional problem-posing opportunities, students may have had a greater number of authentic learning experiences. In addition, consideration should be given to increasing the intervention sessions while reducing the length of the sessions in an attempt to address the focusing issues of several students.

\section{Conclusions}

There are some limitations in this study. Although common themes and patterns were discovered in the instructors' observational notes and interviews, not all the trained research members were interviewed. Only the trained research members who used manipulatives in their instructions were interviewed. If the researchers would have interviewed the other instructors and compared the data derived from the three instructors with that of the instructors who did not use manipulatives when administering problem-posing interventions, there could have been more clear findings on using manipulatives in problem posing. Moreover, some students had received problem-solving intervention during the previous study. Their experiences were excluded from the analyses of the present study, which focused solely on students who received only the problem-posing intervention. However, a further investigation of the problem-solving students' experiences in which researchers interviewed the problem-solving instructors from the previous study and compared the results may allow for a more comprehensive discovery of the benefits of using manipulatives in problem posing.

Overall, using manipulatives made students feel more comfortable posing their own problems, which seemed to match what previous research has been advocating (Carbonneau et al., 2013; Krapp, 2005; Rosen \& Hoffman, 2009). All instructors believed that using manipulatives allowed students to have successful problem-posing learning experience. Students were more motivated and excited to learn when using manipulatives in learning activities. By having their choice to choose their manipulatives to model their mathematical process, it allowed them to be more attentive in learning. When students posed their problems that connected to real life scenarios, it made learning more meaningful. Therefore, using manipulatives to learn mathematical concepts can benefit students in learning how to pose problems. 


\section{References}

Ausubel, D. P. (1963). The psychology of meaningful verbal learning. New York, NY: Grune \& Stratton.

Bruner, J. S. (1964). The course of cognitive growth. American Psychologist, 19(1), 1-15.

Carbonneau, K. K., Marley, S. M., \& Selig, J. P. (2013). A meta-analysis of the efficacy of teaching mathematics with concrete manipulatives. Journal of Educational Psychology, 105(2), 380-400.

Dewey, J. (1938). Experience and education. New York, NY: Macmillan.

El Sayed, R. A. E. (2002). Effectiveness of problem posing strategies on prospective mathematics teachers' problem solving performance. Journal of Science and Mathematics Education in Southeast Asia, 25(1), 56-69.

English, L. D. (1997). The development of fifth-grade children's problem posing abilities. Educational Studies in Mathematics, 34, 183-217. http://dx.doi.org/10.1023/A:1002963618035

Krapp, A. (2005). Basic needs and the development of interest and intrinsic motivational orientations. Learning and Instruction, 15(5), 381-395.

Lowrie, T. (2002). Young children posing problems: The influence of teacher intervention on the type of problems children pose. Mathematics Education Research Journal, 14(2), 87-98.

Miles, M. B., \& Huberman, A. M. (1994). An expanded sourcebook qualitative data analysis. Beverly Hills, CA: Sage.

National Council of Teachers of Mathematics. (1989). Curriculum and evaluation standards for school mathematics. Reston, VA: Author.

National Council of Teachers of Mathematics. (2000). Principles and standards for school mathematics (Vol. 1). Reston, VA: Author.

Piaget, J. (1964). The child's conception of the world. London, UK: Routledge.

Rosen, D., \& Hoffman, J. (2009). Integrating concrete and virtual manipulatives in early childhood mathematics. Young Children, 64(3). 26-33.

Rosli, R., Capraro, M. M., \& Capraro, R. M. (2014). The effects of problem posing on student mathematical learning: A meta-analysis. International Education Studies, 7(13), 227.

Schoenfeld, A. H. (1987). A brief and biased history of problem solving. In F. R. Curcio (Ed.), Teaching and learning: A problem-solving focus (pp. 27-46). Reston VA: National Council of Teachers of Mathematics.

Singer, F., \& Voica, C. (2012). A problem-solving conceptual framework and its implications in designing problem-posing tasks. Educational Studies in Mathematics, 83(1), 9-26.

Stoyanova, E. (2003). Extending students' understanding of mathematics via problem posing. The Australian Mathematics Teacher, 59(2), 32-40.

Van Harpen, X. Y., \& Presmeg, N. C. (2013). An investigation of relationships between students' mathematical problem-posing abilities and their 
mathematical content knowledge. Educational Studies in Mathematics, 83(1), 117-132.

\section{Appendix A Interview Protocol}

1. Tell me about your teaching experience at XXXX ISD. Please describe in detail.

2. When students used manipulatives, what seemed to be pros and cons for the students?

3. Tell me about what you know about using manipulatives in mathematics classrooms. How does this affect your teaching style?

4. Tell me about student experience using manipulatives during problemposing lessons.

a. Did they feel more motivated or excited?

b. Were there any students distracted by the manipulatives?

c. Explain students' behavior when they were using manipulatives.

5. How would you say that manipulatives affected student problemposing strategies?

a. Do you think it would be different if the students were secondary students?

6. I want to take you back to thinking about the first day of the lesson and compare it with the last lesson that involved using manipulatives. How were the students different from the beginning and at the end?

a. Other than their mathematics ability, do you think students were benefited in general? If so, what were the benefits?

Special thanks to Drs. Luciana Barroso, Robert M. Capraro, and Aggie STEM team for providing the data used for this study.

\section{Authors:}

Hyunkyung Kwon

Texas A\&M University \& Aggie STEM, USA

Email:kwonx133@tamu.edu

\section{Mary Margaret Capraro}

Texas A\&M University \& Aggie STEM, USA

Email:mmcapraro@tamu.edu 